\title{
[Review]
}

\section{A CHALLENGE TO APPROPRIATE ANTIBIOTIC USE IN CHILDREN WITH RESPIRATORY INFECTIONS : A 5-YEAR SINGLE-INSTITUTION EXPERIENCE}

\author{
AYUMI MATSUMOTO, KOICHI HASHIMOTO, YUKIHIKO KAWASAKI \\ and MITSUAKI HOSOYA
}

Department of Pediatrics, Fukushima Medical University, Fukushima, Japan

(Received April 11, 2011, accepted June 13, 2011)

\begin{abstract}
:
Background

We have studied the rate of emergence of anitibiotic-resistant Streptococcus pneumoniae (S. pneumoniae) and Haemophilus influenzae (H. influenzae) and the subsequent antibiotic use in host patients of those isolates at the Department of Pediatrics, Soma General Hospital, Fukushima. Moreover, we carried out several studies investigating the risks and benefits of antibioticfree treatment for children with respiratory infections. In this report, we summarize our research and suggest better treatment options for pediatric patients with respiratory infections.

Methods

We investigated the necessity of antibiotic use in the treatment of pediatric inpatients with respiratory syncytial virus (RSV) infection, and tested our hypothesis that antibiotic-free treatment for common cold will reduce the number of resistant $S$. pneumoniae strains in the pediatric nasopharynx. Therefore, we restricted prescribing antibiotics for pediatric patients with respiratory infections. The rates of resistant $S$. pneumoniae and $H$. influenzae and the medication history of the host patients before and after the intervention were compared.

Results

We found that most of the RSV-infected patients recovered without antibiotic treatment, and that the antibiotic-free treatment inhibited the emergence of antibiotic-resistant strains. The rate of penicillin-resistant $S$. pneumoniae decreased but the rate of ampicillin-resistant $H$. influenzae did not change significantly during the study.

Conclusion

We concluded that patients with respiratory infections can be treated without antibiotics, under careful examination and observation. Continued monitoring of such new interventions as well as recommending their use to other caregivers and physicians will help inhibit the spread of resistant strains.
\end{abstract}

Key words : Streptococcus pneumoniae, antibiotics, common cold, children

\section{INTRODUCTION}

Emergence of antibiotic-resistant microbes is a global concern. In pediatrics, the increase in the rate of development of antibiotic resistance in
Streptococcus pneumoniae (S. pneumoniae) and Haemophilus influenzae ( $H$. influenzae) is of great concern, because these bacteria are the major etiologic agents causing serious invasive pediatric infections such as meningitis and septicemia. They are

松本歩美, 橋本浩一, 川崎幸彦, 細矢光亮

Corresponding author : Ayumi Matsumoto, MD E-mail address : b-walk@fmu.ac.jp

http://www.jstage.jst.go.jp/browse/fms http://fmu.ac.jp/home/lib/F-igaku/ 
also responsible for sinusitis, middle ear infections, and pneumonia.

Penicillin-resistant S. pneumoniae was first isolated in the 1980s, and has spread rapidly in Japan $^{1-3)}$. It is well known that penicillin resistance in S. pneumoniae is caused by alteration in the genes encoding penicillin-binding proteins (PBPs), chiefly, $p b p 1 a$, $p b p 2 b$, and $p b p 2 x$. The Japanese pneumococcal isolates often have an altered $p b p 2 x$ gene ; this is considered as the reason for decreasing cephalosporin susceptibility. In other countries, isolates with altered $p b p 1 a$ or $p b p 2 b$ that induce penicillin resistance predominate the clinical scenario ${ }^{2,4-6)}$. The number of ampicillin-resistant $H$. influenzae strains has also increased in our country. This resistance to ampicillin and other betalactam antibiotics in $H$. influenzae has been attributed to the production of beta-lactamase and/or the presence of an alteration in the ftsI gene encoding PBP3. Generally, an ampicillin-resistant $H$. influenzae strain producing beta-lactamase is termed "beta-lactamase-producing ampicillin-resistant" (BLPAR), and the strain that does not produce betalactamase is termed "beta-lactamase-non-producing ampicillin-resistant" (BLNAR). Compared to the other countries with common occurrence of BLPAR isolates, BLNAR isolates predominate in Japan ${ }^{7,8-12)}$.

Over the last 2 decades, worldwide studies have been carried out on the risk factors associated with carriage of resistant strains; the most important factor was found to be previous antibiotic use $^{13-27)}$. Moreover, studies since the late 1990s have reported about campaigns to promote appropriate antibiotic use ${ }^{28-34)}$. Contrary to the international scenario, oral cephalosporin has been commonly used for treating children with respiratory infections without signs of bacterial infection in Japan. It is suggested that cephalosporin overuse has caused the alteration of $p b p$ genes in both $S$. pneumoniae and H. influenzae ${ }^{1-3)}$.

We investigated the rate of resistant $S$. pneumoniae and $H$. influenzae and the medication history of the host patients of those isolates at the pediatric department of Soma General Hospital, Fukushima. We discovered that, throughout our investigation, the prevalence of resistant isolates was extremely high. We started to reduce antibiotic use in patients with respiratory infections, and have used amoxicillin rather than cephalosporin antibiotics as a first choice for empirical therapy of respiratory infections since 2004. We chose amoxicillin because it has some positive pharmacokinetic properties $^{35-38)}$. We also performed the studies to inve- stigate questions like "Will patients recover without problems even if they do not receive antibiotics ?" and "Will the resistant strain truly vanish from host children after an antibiotic-free term ?" The clinical trial was designed to answer these questions.

Conjugate vaccines of $S$. pneumoniae and $H$. influenzae type $\mathrm{b}$ have now been introduced; it is time to reconsider the use of antibiotics. The purpose of this report is to review 5 years of promoting appropriate antibiotic use, and to consider how to treat pediatric patients with respiratory infections in this new era of preventive medicine.

\section{STUDIES}

\section{1) The prevalence of resistant $S$. pneumoniae and $H$. influenzae strains in the initial 2 years, and the associated host risk factors}

This first study was performed from September 2001 to June 2003. We had prescribed cephalosporin antibiotics for pediatric outpatients with respiratory infections. The aims of the study were to investigate the rate of antibiotic prescription, the antimicrobial susceptibility of $S$. pneumoniae and $H$. influenzae isolates, and the risk factors associated with the carriage of resistant strains. During the study period, the annual pediatric patient number was about 20,000, and we collected nasopharyngeal swabs from patients with respiratory tract infections.

Of all cases, previous oral antibiotic use was reported in $54.4 \%$, and oral administration of cephalosporin was reported in $20.8 \%$. Of the $949 \mathrm{~S}$. pneumoniae isolates, 443 isolates $(46.7 \%)$ were intermediate-resistant $(0.12-1.0 \mathrm{mg} / \mathrm{L})$, and 321 isolates $(33.8 \%)$ were resistant $(\geq 2.0 \mathrm{mg} / \mathrm{L})$, according to the previous susceptibility breakpoints set by the National Committee for Clinical Laboratory Standards (NCCLS). Gene detection was performed in 226 randomly chosen isolates. Of the 226 isolates, 200 isolates $(88.5 \%)$ had 1 or more altered $p b p$ gene(s) ${ }^{39,40)}$. Moreover, of the $791 \mathrm{H}$. influenzae isolates detected, 81 isolates (10.2\%) were BLNAR, and 61 isolates $(7.7 \%)$ were BLPAR; thus, 142 (17.9\%) isolates were ampicillin-resistant ${ }^{39,41)}$.

Data of the background of the host patients, including previous use of antibiotics, age, daycare attendance, and siblings, were taken into consideration using a questionnaire and/or referring to medical records. The relation between carriage of $S$. pneumoniae isolates with 1 or more $p b p$ genes and each risk factor was analyzed. Antibiotic use in the 
last 3 months in children (2 years of age and younger) was substantially related with the carriage of resistant isolates $(p<0.01)$. Children with daycare exposure tended to carry resistant strains $(p=0.06)$ (Table 1). Fig. 1 shows that previous antibiotic use was significantly correlated with the alteration of $p b p$ genes. Orally administered cephalosporin and macrolide antibiotics were significantly related to isolates with 1-point $p b p$ alteration $(p<0.01)$. Other antibiotics, including fosfomycin and minocyclin, were also significantly related to isolates with more than 2-point $p b p$ alteration $(p<0.01)^{40)}$.
2) The risks and benefits of appropriate antibiotic use : The experience of the antibiotic-free treatment for inpatients with a lower respiratory infection caused by respiratory syncytial virus

Our first study revealed a high rate of resistant isolates in our department. We considered that overuse of cephalosporin antibiotics exacerbated this problem. Although we tried to restrict antibiotic use in pediatric patients with respiratory infections, we were concerned about the risks of antibiotic-free treatment. In order to evaluate antibioticfree treatment, we investigated the necessity of antibiotic use in the treatment of pediatric inpatients

Table 1. Risk factors for carriage of Streptococcus pneumoniae with altered pbp genes

\begin{tabular}{ccc} 
& & $N=226$ \\
\hline Risk factor & $N[\%]^{*}$ & $P$ value \\
\hline 2 years of age and younger & $146[64]$ & $<0.01$ \\
Sibling & $99[44]$ & 0.11 \\
Day care center exposure & $61[27]$ & 0.06 \\
Use of antibiotics within the last 3 month & $125[55]$ & $<0.01$ \\
\hline
\end{tabular}

"indicates Numbers of patients having Streptococcus pneumoniae with altered pbp genes.

The $\chi^{2}$ test was performed for comparing the backgrounds of the children with the resistant strain and those children with a susceptible strain. The result was considered statistically significant if the value of $P$ was less than 0.05 .

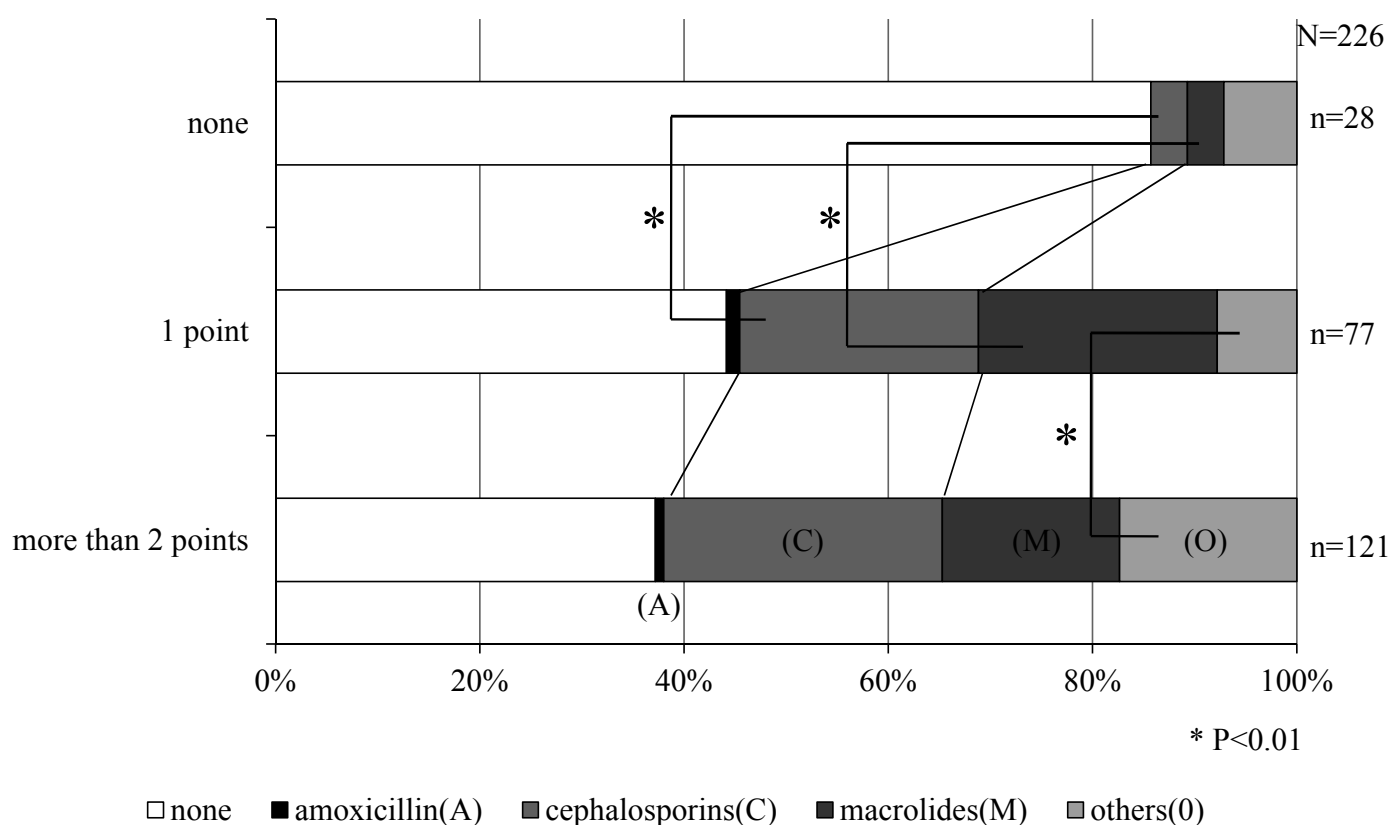

Fig. 1. The relation between antibiotic history and carriage of Streptococcus pneumoniae with altered pbp gene(s) in a study performed from 2001 to 2003.

"Others" includes fosfomycin and minocyclin. The virtual line indicates the number of $p b p$ gene alterations. The $\chi^{2}$ test was performed for comparing the antibiotic history of patients with resistant isolates with that of patients with susceptible isolates. "indicates a p value less than 0.01 . 
with respiratory syncytial virus (RSV) infection, from 2003 to 2004 . Sixty cases diagnosed as RSV infection by the rapid antigen test were involved in this study. We compared the duration of fever and hospitalization and the cost of hospitalization between patients treated with and without antibiotics. The duration of fever and the cost of hospitalization were similar in the group treated with antibiotics (antibiotic treatment group) and the group treated without antibiotics (antibiotic-free treatment group). However, the duration of hospitalization was longer in the antibiotic-free treatment group. Furthermore, in case of nasopharyngeal S. pneumoniae and/or $H$. influenzae isolates, the duration of hospitalization was significantly longer in the antibiotic-free treatment group (Table 2). Two patients in the antibiotic-free treatment group failed to recover without antibiotics. They showed no improvements in the symptoms and laboratory findings 5 days after admission; therefore, we administered antibiotics.

Our study showed that it was possible to treat most cases without antibiotics. However, it also suggests that antibiotics can decrease the duration of hospitalization in cases involving bacterial isolates, and that some patients fail to recover without antibiotics. We concluded that we could, in principle, treat patients with viral respiratory infections without antibiotics, but that these patients should be observed very closely for complications of bacterial infection $^{42)}$.

\section{Will an antibiotic-free term reduce the rate of resistant pneumococci?}

The benefits of restricting antibiotic use are unclear. From 2003 to 2004, we tried to demonstrate that antibiotic-free treatment for the common cold will reduce the rate of antibiotic-resistant $S$. pneumoniae in the pediatric nasopharynx. Fortyfive children diagnosed with common cold were randomly selected from pediatric patients who had consumed antibiotics in the past 3 months. We collected nasopharyngeal swabs from all the participants before and after an antibiotic-free period of 2-3 months. S. pneumoniae strains were isolated from 24 of these patients. Susceptibility tests and detection assays for drug-resistant genes were performed on these strains. All the patients recovered without complications. The susceptibility test revealed that patients with penicillin-resistant isolates decreased in number from 17 to $7(p<0.01)$. The test also revealed that these patients had cefditoren-resistant isolates. Figure 2 shows the dynamics of $p b p$ gene alteration in $S$. pneumoniae in these 24 patients. The graph clearly shows that no patients had the isolate-acquired altered $p b p$ gene(s). We found that the number of altered $p b p$ genes had decreased in 11 patients, and that the remaining isolates had the same gene(s) as the rest of the patients did. Our study suggests that antibiotic-free treatment inhibits the emergence of penicillin-resistant S. pneumoniae ${ }^{43)}$.

Table 2. Comparison between the antibiotic-use group and the non-antibiotic group

\begin{tabular}{cccc}
\hline & $\begin{array}{c}\text { the non-antibiotic group } \\
N[\%], \text { the mean }\end{array}$ & $\begin{array}{c}\text { the antibiotic-use group } \\
N[\%], \text { the mean }\end{array}$ & $P$ value \\
\hline total & $\mathbf{3 0}$ & $\mathbf{3 0}$ & \\
the duration of fever (days) & 3.1 & 3 & 0.94 \\
the duration of hospitalization (days) & 6.1 & 5.4 & $\mathbf{0 . 0 2 8}$ \\
the cost for hospitalization (yen) & 167,000 & 163,000 & 0.561 \\
The cases with isolates & $\mathbf{1 3}[\mathbf{4 3 . 3}$ & $\mathbf{1 8}[\mathbf{6 0 . 0}$ & \\
the duration of fever (days) & 4.3 & 3.3 & 0.074 \\
the duration of hospitalization (days) & 6.3 & 5.2 & $\mathbf{0 . 0 2 4}$ \\
the cost for hospitalization (yen) & 173,000 & 156,000 & 0.165 \\
The cases without isolates* & $\mathbf{1 7}[\mathbf{5 6 . 7}$ & $\mathbf{1 2}[\mathbf{4 0 . 0}$ & \\
the duration of fever (days) & 1.9 & 2.5 & 0.44 \\
the duration of hospitalization (days) & 5.9 & 5.6 & 0.546 \\
the cost for hospitalization (yen) & 162,000 & 171,000 & 0.543 \\
\hline
\end{tabular}

"indicates the cases with $S$. pneumoniae and /or H. influenzae isolates from their nasopharynx

***indicates the cases without isolates of S. pneumoniae and /or H. influenzae

The $\chi^{2}$ test was performed for comparing the results of the non-antibiotic group and the antibiotic-use

group. The result was considered statistically significant if the value of $P$ was less than 0.05 . 
3) Studies during the intervention involving a reduction in antibiotic use :

The prevalence of resistant $S$. pneumoniae and $H$. influenzae

On the basis of our previous studies, in 2004, we decided to promote appropriate antibiotic use. Physicians working at Soma General Hospital

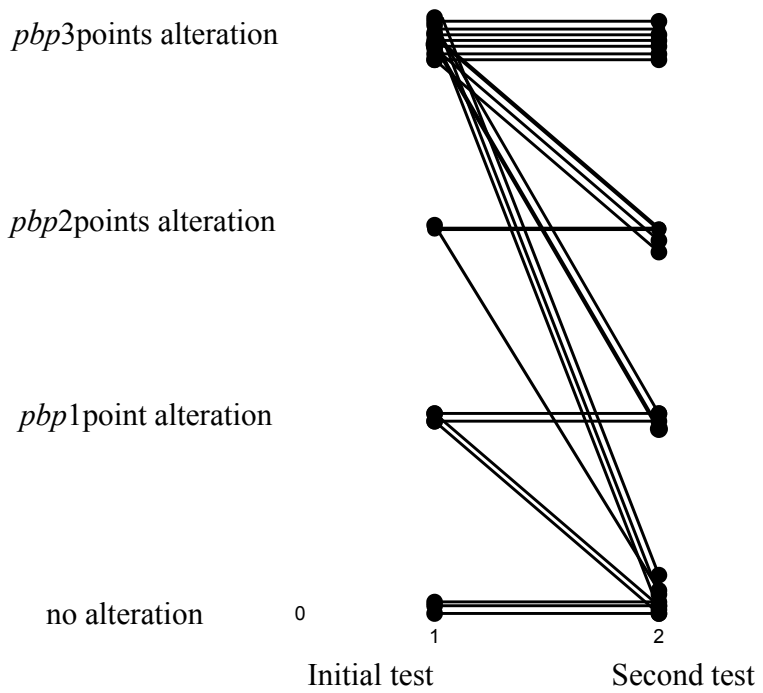

Fig. 2. Changes in the $p b p$ gene alteration pattern of Streptococcus pneumoniae between the first and second tests in individuals.

Each black dot represents 1 patient. minimized the prescription of antibiotics to pediatric outpatients with respiratory infections. When the cases necessitated antibiotic use, we administered amoxicillin as a first choice for empirical therapy. We again investigated the rate of penicillinresistant S. pneumoniae from 2004 to 2006 . There were 1190 isolates of $S$. pneumoniae. Of the 1190 isolates, $525(44.2 \%)$ isolates were intermediateresistant, and $332(27.9 \%)$ isolates were resistant, according to previous susceptibility breakpoints. Compared to the previous study (2001-2003), the rate of resistant isolates showed a decrease of 5.9\% $(p<0.01)$, whereas the rate of susceptible isolates showed an increase of $8.5 \%(p<0.01)$ (Fig. 3). Gene detection was performed for 202 randomly chosen isolates. Table 3 shows the results of gene detection ; gene alteration was observed in $15.5 \%$ isolates in the 2001-2003 study and in $21.8 \%$ isolates in the latter study $(p=0.09)$. The percentage of isolates with more than 2 altered $p b p$ genes did not change significantly during the studies ${ }^{44}$.

We also investigated 1137 isolates of $\mathrm{H}$. influen$z a e$ from 2004 to 2006. Of the 1137 isolates, 119 (10.5\%) isolates were BLNAR, and 63 (5.5\%) isolates were BLPAR. Thus, the total percentage of ampicillin-resistant isolates was $18 \%$, and did not statistically differ from the results of a previous study ${ }^{45)}$.

These studies showed some improvements in

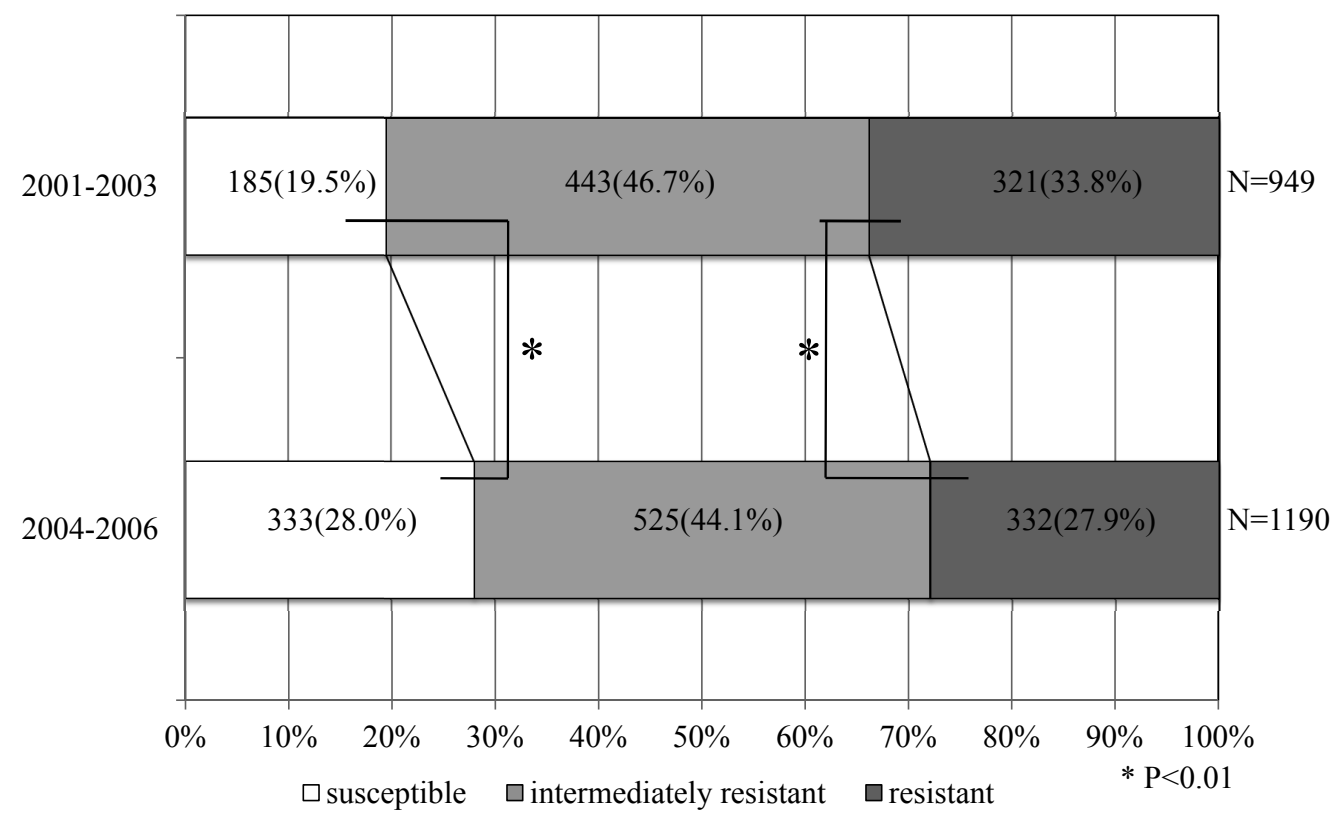

Fig. 3. The rates of penicillin-resistant Streptococcus pneumoniae in the former study performed from 2001 to 2003 and in the latter study performed from 2004 to 2006 "Susceptible" indicates penicillin-susceptible isolates $(\mathrm{MIC}<0.12 \mathrm{mg} / \mathrm{L})$, "intermediate-resistant" indicates isolates with intermediate resistance to penicillin $(\mathrm{MIC}=0.12-0.10 \mathrm{mg} / \mathrm{L})$, and "resistant” indicates penicillin-resistant isolates $(\mathrm{MIC} \geq 2.0 \mathrm{mg} / \mathrm{L})$. 
the carriage of resistant strains in children. However, changes were not as obvious as predicted. Findings might show only a small incidence of S. pneumoniae resistance, even though we tried to reduce antibiotic use. Moreover, the carriage of resistant strains is expected to be influenced by the prescribing habits of the physicians in the surrounding areas. This research should be continued to monitor the trends in development of resistance.

\section{Is amoxicillin a safe alternative?}

We have investigated the antibiotic history of host patients of $S$. pneumoniae and $H$. influen$z a e$. Fig. 4 shows the rate of antibiotic use in the 2001-2003 and 2004-2006 studies. The total rate of antibiotic use did not decrease significantly during the 2 tests. As we have used amoxicillin as a first choice for empirical therapy of respiratory infection, the frequency of amoxicillin use was much higher than that of cephalosporin antibiotics. Fig. 5 exhibits the obvious correlation between amoxicillin use and the accretion of $p b p$ genes in S. pneumoniae. It suggests that development of resistance in these isolates might have been influenced by amoxicillin, which was used more frequently than cephalosporin antibiotics.

Some researchers previously reported the relation between alteration of $p b p$ genes and the development of amoxicillin resistance in the clinical isolates of $S$. pneumoniae $e^{46-48)}$. We are concerned that

Table 3. The results of $p b p$ gene detection

\begin{tabular}{ccc}
\hline & $2001-2003 N=226$ & $2004-2006 N=202$ \\
& $n[\%]^{*}$ & $n[\%]^{*}$ \\
\hline none & $\mathbf{2 6}[\mathbf{1 1 . 5}]$ & $\mathbf{2 0}[\mathbf{9 . 9}]$ \\
an altered $\boldsymbol{p} \boldsymbol{b} \boldsymbol{p}$ gene & $\mathbf{3 5}[\mathbf{1 5 . 5}]$ & $\mathbf{4 4}[\mathbf{2 1 . 8}]$ \\
pbp1a & 0 & $1[0.5]$ \\
pbp2b & 0 & $2[1.0]$ \\
pbp2x & $35[15.5]$ & $41[20.3]$ \\
more than two altered $\boldsymbol{p} \boldsymbol{b} \boldsymbol{p}$ gene & $\mathbf{1 6 5}[\mathbf{7 3 . 0}]$ & $\mathbf{1 3 8}[\mathbf{6 8 . 3}]$ \\
pbp1a+2x & $20[8.8]$ & $16[7.9]$ \\
pbp2x+2b & $24[10.6]$ & $14[6.9]$ \\
pbp1a $+2 \mathrm{x}+2 \mathrm{~b}$ & $121[53.5]$ & $108[53.5]$ \\
\hline
\end{tabular}

"Numbers of Streptococcus pneumoniae isolates.

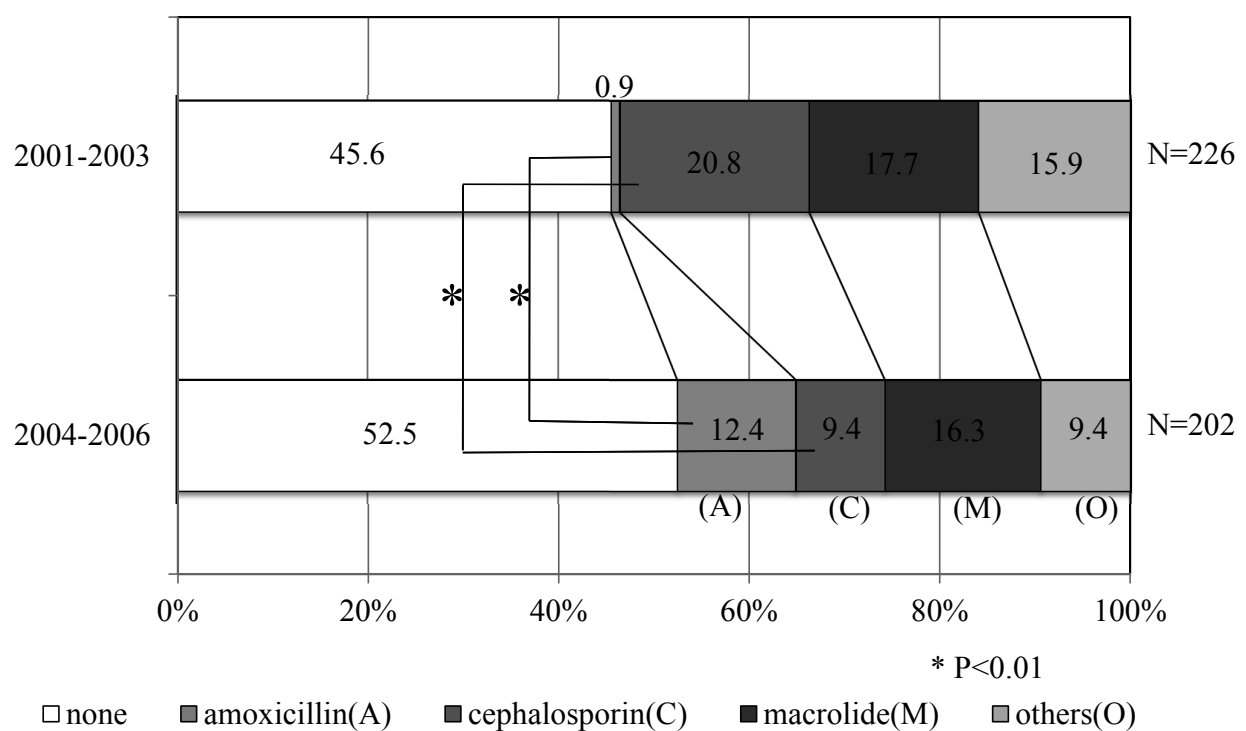

Fig. 4. The classification of antibiotics administered to the host patients of Streptococcus pneumoniae in the past 3 months.

"Others" includes fosfomycin and minocyclin. The numbers indicate the percentage of number of patients in each category. The $\chi^{2}$ test was performed for comparing the results of the former and latter studies. "indicates a $p$ value less than 0.01 . 


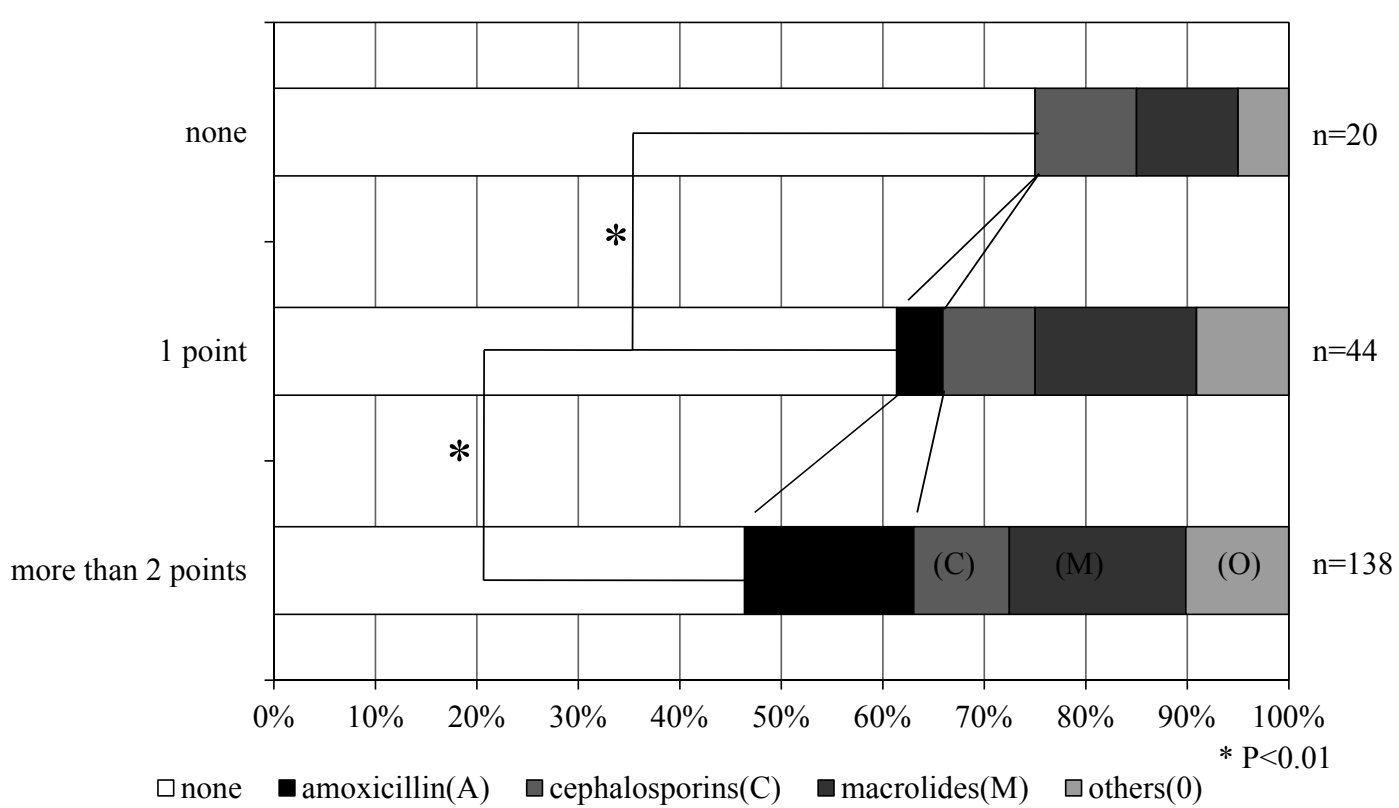

Fig. 5. The relation between antibiotic history and carriage of Streptococcus pneumoniae with altered $p b p$ gene(s) in the study performed from 2004 to 2006.

"Others" includes fosfomycin and minocyclin. The virtual line indicates the number of $p b p$ gene alterations. The $\chi^{2}$ test was performed for comparing the antibiotic history of patients with resistant isolates with that of patients with susceptible isolates. "indicates a $p$ value less than 0.01 .

amoxicillin is not a safe alternative to prevent the emergence of resistant strains. The research should proceed to clarify the relation between amoxicillin use and resistance development in S. pneumoniae, which is essential for the reassessment of a beneficial approach for the treatment of pediatric respiratory infections ${ }^{44,45)}$.

The problem with the indication for macrolide antibiotics

Figure 4 shows the rate of use of macrolide antibiotics in both studies. The rate was $16.3 \%$ in the latter study, and it did not significantly differ from that observed in the initial study (20012003). We considered that one of the reasons that physicians frequently decide to prescribe macrolide antibiotics is concern over possible Mycoplasma pneumoniae or Bordetella pertussis infections. These respiratory infections are important examples of indication for macrolide antibiotics, and it is difficult for physicians to diagnose these infections only on the basis of physical findings. A previous study explained that macrolide antibiotics have an intense effect on $S$. pneumoniae resistance against both beta-lactam and macrolide antibiotics ${ }^{49}$. In our former study, macrolide antibiotic use was obviously related to the alteration of $p b p$ genes (Fig. 1, Fig. 5), unlike in the latter study. Further investigation is required to clarify how macrolide antibiotics affect resistance not only to macrolide antibiotics but also to beta-lactam antibiotics. The method used to rule out the indication for macrolide antibiotics when we treat patients with respiratory infections also needs to be reconsidered.

\section{CONSIDERATIONS}

\section{Can we prescribe fewer antibiotics?}

Despite intervention for restrictive antibiotic use, $47.5 \%$ of patients with respiratory infection were still administered antibiotics. It is necessary to reconsider the techniques used to promote appropriate use of antibiotics. Previous studies reported that the leading cause of physicians prescribing antibiotics was parents' request ${ }^{31,50-56)}$. The parents' lack of knowledge about proper antibiotic use can, therefore, be expected to cause inappropriate antibiotic prescription. However, even when parents have a good understanding of the issue, physicians tend to prescribe antibiotics, because they perceive parents' queries about the treatment plan as an expectation for antibiotic use $\mathrm{e}^{50,53,54)}$. A previous study reported that parents were satisfied when the physicians took what they perceived as an adequate amount of time to examine their child, regardless of 
whether an antibiotic was subsequently prescribed $^{577}$. It is necessary for physicians to be aware of the parents' beliefs and to improve their communication skills.

Diagnostic uncertainty also results in inappropriate antibiotic use ${ }^{54)}$. Currently, quick and easy devices for detecting antigens of etiological agents such as Mycoplasma, influenza virus, RSV, and adenovirus, are being developed. This should allow physicians to rule out the need for antibiotic use. Some studies reported a "wait-and-see" strategy for middle ear infections ${ }^{58-63)}$. They concluded that most patients with non-severe middle ear infections recover without antibiotics. However, antibioticfree treatment is not risk free. Another study proposing the "wait-and-see" strategy for middle ear infection mentioned that children who failed to improve without antibiotics were younger than those who improved, and were colonized with pathogens $^{63)}$. In our study of antibiotic-free therapy for inpatients with RSV infection, we found that isolation of nasopharyngeal strains of S. pneumoniae and/ or H. influenzae was a risk factor for the failure of antibiotic-free treatment ${ }^{42)}$. We considered that a "wait-and-see" strategy would work for pediatric patients with non-severe viral respiratory infections. The chief point is to carefully monitor the patients while waiting for treatment response. Further studies need to be performed to develop a tool to predict the patients who will recover without antibiotic use.

The introduction of vaccines against S. pneumoniae and $H$. influenzae

An H. influenzae type b (Hib) conjugate vaccine, first developed in the late 1980s, has been in worldwide use. The World Health Organization (WHO) has recommended a national routine immunization schedule including the Hib vaccine since $1998^{64,65)}$. Previous studies reported that the incidence of Hib disease had decreased after the introduction of routine immunization ${ }^{66-72)}$. A pneumococcal conjugate vaccine including 7 serotypes has been available since 2000. The WHO has also recognized the safety and effectiveness of the pneumococcal vaccine, and has recommended the vaccine to be included in national immunization programs ${ }^{73}$. Routine immunization with pneumococcal vaccine has showed a decreased incidence of vaccine-type pneumococcal invasive diseases and nasopharyngeal colonization in vaccinated individuals ${ }^{73-83)}$. The costs and benefits of these vaccines have been well investigated in previous studies; most studies showed that routine immunization with these vaccines is cost effective ${ }^{84-87)}$. The previous report also proved the cost-effectiveness of using Hib vaccine in our country ${ }^{88}$.

The arrival of Hib and pneumococcal conjugate vaccines in Japan will influence the methods used for ruling out the indication for antibiotics. A previous study showed that physicians prescribe antibiotics less frequently in vaccinated patients than in patients who have not been vaccinated ${ }^{89}$. The vaccines may contribute not only to decrease the incidence of invasive diseases caused by $S$. pneumoniae and $H$. influenzae but also to decrease antibiotic prescription for pediatric patients.

\section{LIMITATIONS}

Our studies had several limitations. First, the method used to isolate $S$. pneumoniae strains could cause a possible bias, because only a single colony of $S$. pneumoniae was examined from each patient. Since the nasopharyngeal strains are considered to have varied susceptibilities to antibiotics, a single colony might not provide a representative resistance rate. It would be logical to assume that we investigated only the predominant strains. Second, the term of patient's symptoms might be biased. For example, during antibiotic-free treatment for inpatients with RSV infection, we had administered antibiotics on day 5 of fever, and the duration of fever was possibly limited because of antibiotic use. Since the studies were performed clinically, priority must be given to patient recovery. It is, therefore, difficult to present a definitive outcome of antibioticfree treatment. When planning the next study, we need to consider the design of the study from different angles. Third, it is not appropriate to generalize from our results because the studies were performed at a single institution. Reports about promoting proper antibiotic use need to be generated from different areas, and the facts and findings from these reports should be considered when we apply our particular experience to actual medical examinations.

\section{CONCLUSION}

We reviewed a 5-year period of intervention for appropriate antibiotic use at a single institution. During this period, we found that an antibiotic-free term inhibited the emergence of antibiotic-resistant strains. We also found that although most pediatric patients with respiratory infections recovered with- 
out antibiotic treatment, few patients did not. We concluded that a "wait-and-see" strategy would work for patients with respiratory infections under conditions of careful examination and observation. Despite the intervention, we could not reduce the rate of antibiotic prescription as expected. We should recommend such interventions to colleagues as well as to caregivers and physicians in the surrounding areas. It is highly necessary to educate the parents so that they understand appropriate use of antibiotics, and to improve the physicians' communication skills. It is also important to inform the physicians about the rate of resistance to maintain awareness about appropriate use of antibiot$\mathrm{ics}^{90-96)}$. The methods used for ruling out the indication for antibiotics are bound to change in this new era. Using rapid antigen tests, physicians can easily exclude patients testing positive for a viral infection. They also need to consider whether patients have been vaccinated for $S$. pneumoniae and $H$. influenza.

Medicine has long benefitted from the use of antibiotics. However, we are now faced with the victims of resistant microbes that have been generated by the overuse of antibiotics. Reducing inappropriate antibiotic use is a very difficult task for physicians. However, there are suggestions on the possible methods to achieve this in pediatric patients. A previous report concluded that treatment plans should focus on making a child feel better, rather than on antibiotic use ${ }^{52}$. We believe that the problems of inappropriate use of antibiotics and emergence of resistant strains will be improved by this fundamental step in the pediatric treatment.

\section{ACKNOWLEDGMENTS}

We would like to thank Kyoko Hirasawa and Kumiko Sugama of the Bacteriological Laboratory of Fukushima Institute of Public Health, and Kiyohiko Watanabe and Kinuko Ara of the Bacteriological Laboratory of Soma General Hospital for their technical support.

\section{REFERENCES}

1. Ubukata K. Problems associated with high prevalence of multidrug-resistant bacteria in patients with community-acquired infections. J Infect Chemother, 9 : 285-291, 2004.

2. Ubukata K, Chiba N, Hasegawa K, Kobayashi R, Iwata S, Sunakawa K. Antibiotic susceptibility in relation to penicillin-binding protein genes and serotype distribution of Streptococcus pneumoniae strains responsible for meningitis in Japan, 1999 to 2002. Antimicrob Agents Chemother, 48 : 14881494, 2004.

3. Chiba N, Kobayashi N, Hasegawa K, Morozumi M, Nakayama E, Tajima T, Iwata S, Ubukata K. Antibiotic susceptibility according to genotype of penicillin-binding protein and macrolide resistance genes, and serotype of Streptococcus pneumoniae isolates from community-acquired pneumonia in children. J Antimicrob Chemother, 56 : 756-760, 2005.

4. Asahi Y, Takeuchi Y, Ubukata K. Diversity of substitutions within or adjacent to conserved amino acid motifs of penicillin-binding protein $2 \mathrm{X}$ in cephalosporin-resistant Streptococcus pneumoniae isolates. Antimicrob Agents Chemother, 43 : 12521255, 1999.

5. Nagai K, Shibasaki Y, Hasegawa K, Davies TA, Jacobs MR, Ubukata K, Appelbaum PC. Evaluations of the primers for PCR to screen Streptococcus pneumoniae isolates, $\beta$-lactam resistance and to detect common macrolide resistance determinants. J Antimicrob Chemother, 48 : 915-918, 2001.

6. du Plessis M, Bingen E, Klugman KP. Analysis of penicillin-binding protein genes of clinical isolates of Streptococcus pneumoniae with reduced susceptibility to amoxicillin. Antimicrob Agents Chemother, 46 : 2349-2357, 2002.

7. Tristram S, Jacobs MR, Appelbaum PC. Antimicrobial resistance in Haemophilus influenza. Clin Microbiol Rev, 20 : 368-389, 2007.

8. Hotomi M, Fujihara K, Billal DS, Suzuki K, Nishimura T, Baba S, Yamanaka N. Genetic characteristics and clonal dissemination of beta-lactamase-negative ampicillin-resistant Haemophilus influenzae strains isolated from the upper respiratory tract of patients in Japan. Antimicrob Agents Chemother, 51 : 3969-3976, 2007.

9. Hashida K, Shiomori T, Hohchi N, Muratani T, Mori T, Udaka T, Suzuki H. Nasopharyngeal Haemophilus influenzae carriage in Japanese children attending day-care centers. J Clin Microbiol, 46: 76-81, 2008.

10. Hasegawa K, Kobayashi R, Takada E, Ono A, Chiba N, Morozumi M, Iwata S, Sunakawa K, Ubukata K. High prevalence of type $b$ beta-lactamasenon-producing ampicillin-resistant Haemophilus influenzae in meningitis: the situation in Japan where Hib vaccine has not been introduced. J Antimicrob Chemother, 57 : 1077-1082, 2006.

11. Kubota T, Higa F, Kusano N, Nakasone I, Haranaga S, Tateyama M, Yamane N, Fujita J. Genetic analysis of beta-Lactamase negative ampicillin-resistant strains of Haemophilus influenzae isolated in 
Okinawa, Japan. Jpn J Infect Dis, 59 : 36-41, 2006.

12. Hasegawa K, Chiba N, Kobayashi R, Murayama SY, Iwata S, Sunakawa K, Ubukata K. Rapidly increasing prevalence of beta-lactamase-nonproducing, ampicillin-resistant Haemophilus influenzae type $\mathrm{b}$ in patients with meningitis. Antimicrob Agents Chemother, 48 : 1509-1514, 2004.

13. Ussery XT, Gessner BD, Lipman H, Elliott JA, Crain MJ, Tien PC, Parkinson AJ, Davidson M, Facklam RR, Braiman RF. Risk factors for nasopharyngeal carriage of resistant Streptococcus pneumoniae and detection of a multiply resistant clone among children living in the Yukon-Kuskukwim Delta Region of Alaska. Pediatr Infect Dis J, 15 : 986-992, 1996.

14. Arnold KE, Leggiadro RJ, Breiman RF, Lipman HB, Schwartz B, Appleton MA, Cleveland KO, Szeto HC, Hill BC, Tenover FC, Elliot JA, Facklam RR. Risk factors for carriage of drug-resistant Streptococcus pneumoniae among children in Memphis, Tennessee. J Pediatr, 128 : 757-764, 1996.

15. Arason VA, Kristinsson KG, Sigurdsson JA, Stefánsdóttir G, Möslad S, Gudmundsson S. Do antimicrobials increase the carriage rate of penicillin resistant pneumococci in children ? Cross sectional prevalence study. BMJ, 313 : 387-391, 1996.

16. Clavo-Sánchez AJ, Girón-González JA, LópezPrieto D, Canuetto-Quentero A, Marin-Casanova P, Córdoba-Dofia JA. Multivariate analysis of risk factors for infection due to penicillin-resistant and mutidrug-resistant Streptococcus pneumoniae: A multicenter study. Clin Infect Dis, 24: 10521059, 1997.

17. Kristinsson KG. Effect of antimicrobial use and other risk factors on antimicrobial resistant in pneumococci. Microb Drug Resist, 3 : 117-123, 1997.

18. Melander E, Mölstad S, Pesson K, Hasson HB, Söderstöm M, Ekdahl K. Previous antibiotic consumption and other risk factors for carriage of penicillin-resistant Streptococcus pneumoniae in children. Eur J Microbiol Infect Dis, 17 : 834-838, 1998.

19. Deeks SL, Palasio R, Ruvinsky R, Kertesz DA, Hortal M, Rossi A, Sika JS, Fabio JLD, The Streptococcus pneumoniae Working Group. Risk factors and course of illness among children with invasive penicillin-resistant Streptococcus pneumoniae. Pediatrics, 103 : 409-413, 1999.

20. Syrogiannopoulos GA, Grivea IN, Tavies TA, Katopodis GD, Applebaum PC, Bertis N. Antimicrobial use and colonization with erythromycinresistant Streptococcus pneumoniae in Greece during the first 2 years of life. Clin Infect Dis,
311 : 887-932, 2000.

21. Samore MH, Magill MK, Alder SC, Severina E, Boer LM, Lyon JL, Carroll K, Leary J, Stone MB, Bradford D, Reading J, Tomasz A, Sande MA. High rates of multiple antibiotic resistance in Streptococcus pneumoniae from healthy children living in isolated rural communities: Association with cephalosporin use and intrafamilial transmission. Pediatrics, 108 : 856-865, 2001.

22. Pihlajamaki M, Kotilainen P, Kaurila T, Palva E, Huovinen P, the Finnish Study Group for Antimicrobial Resistance. Macrolide-resistant Streptococcus pneumoniae and use of antimicrobial agents. Clin Infect Dis, 33 : 483-488, 2001.

23. Marc L. Measuring and interpreting associations between antibiotic use and penicillin resistance in Streptococcus pneumoniae. Clin Infect Dis, 32 : 1044-1054, 2001.

24. Lipsitch M, Samore M. Antibiotic use and antimicrobial resistance: A population perspective. Emerg Infect Dis, 8 : 342-354, 2002.

25. Nasrin D, Collignon PJ, Roberts L, Wison EJ, Piotto LS, Douglas RM. Effect of $\beta$-lactam antibiotic use in children on pneumococcal resistance to penicillin: morospective cohort study. BMJ, 324 : 28-30, 2002.

26. Beekmann EE, Diekema D, Heilmann KP, Richter SS, Doer GV. Macrolide use identified as risk factor for macrolide-resistant Streptococcus pneumoniae in a 17-center case-control study. Eur J Clin Microbiol Infect Dis, 6 : 33-44, 2006.

27. Guillemot D, Carsbon C, Balkau B, Geslin P, Lecoeur H, Vauzelle-Kervroedan F, Bouvenot G, Ecshwege E. Low dosage and long treatment duration of $\beta$-lactam. Risk factors for carriage of penicillin-resistant Streptococcus pneumoniae. JAMA, 279 : 365-370, 1997.

28. Bauchner H, Philipp B. Reducing inappropriate oral antibiotic use: A prescription for change. Pediatrics, 102 : 142-144, 1998.

29. Bauchner H, Besser RE. Promoting the appropriate use of oral antibiotics: There is some very good news. Pediatrics, 111 : 668-670, 2003.

30. Dowell SF, Marcy MS, Phillips WR, Gerber MA, Schwartz B. Principles of judicious use of antimicrobial agents for pediatric upper respiratory tract infections. Pediatrics, 101 : 163-165, 1998.

31. Bauchner H, Pelton SI, Klein JO. Parents, physicians, and antibiotic use. Pediatrics, 103: 395401, 1999.

32. Pichichero ME, Green JL, Francis AB, Marsocci SM, Murphy ML. Outcomes after judicious antibiotic use for respiratory tract infections seen in a private pediatric practice. Pediatrics, 105: 753$759,2000$.

33. Finkelstein JA, Stille C, Nordin J, Davis R, Raebel 
MA, Roblin D, Go AS, Smith D, Johnson CC, Kleinman K, Chan KA, Platt R. Reduction in antibiotic use among US children, 1996-2000. Pediatrics, 112 : 620-627, 2003.

34. Finkelstein JA, Davis RL, Dowell SF, Metlay JP, Soumerai SBS, Rifas-Shiman SL, Higham M, Miller Z, Miroshnik I, Pedan A, Platt R. Reducing antibiotic use in children : a randomized trial in 12 practices. Pediatrics, 108 : 1-7, 2001.

35. Jacobs MR, Bajaksouzian S, Zilles A, Lin G, Pankuch GA, Appelbaum PC. Susceptibilities of Streptococcus pneumoniae and Haemophilus influenzae to 10 oral antimicrobial agents based on pharmacodynamic parameters : 1997 US surveillance study. Antimicrob Agents Chemother, 43 : 19011908, 1999.

36. Jacobs MR, Flemingham D, Appelbaum PC, Gruneberg RN. The Alexander Project 19982000: Susceptibility of pathogens isolated from community-acquired respiratory tract infection to commonly used antimicrobial agents. J Antimicrob Chemother, 52 : 229-246, 2003.

37. Klimek JJ, Nightingale C, Lehmann WB, Quintiliani $\mathrm{R}$. Comparison of concentrations of amoxicillin and ampicillin in serum and middle ear fluid of children with chronic otitis media. J Infect Dis, 135 : 999-1002, 1977.

38. Sutherland R, Croydon EAP, Rolinson GN. Amoxycillin : a new semisynthetic penicillin. Br Med J, 3 : 13-16, 1972.

39. Matsumoto A, Hosoya M, Katayose M, Hiromichi M, Kawasaki Y, Sato K, Kato K, Suzuki H. Antimicrobial resistance in Streptococcus pneumoniae and Haemophilus influenzae isolated from nasopharynx in children. Kansenshogaku Zasshi, 78 : 482-489, 2004.

40. Matsumoto A, Hosoya M, Kawasaki Y, Katayose M, Kato K, Suzuki H. The emergence of drug-resistant Streptococcus pneumoniae and host risk factors for carriage of drug-resistant genes in the northeastern region of Japan. Jpn J Infect Dis, 60 : 1013, 2007.

41. Matsumoto A, Hosoya M, Katayose M, Watanabe $\mathrm{K}$, Kato K, Suzuki H. Host risk factors for acquirement of antimicrobial resistant gene in Haemophilus influenzae. Kansenshogaku Zasshi, 79 : 249-253, 2005.

42. Matsumoto A, Hosoya M, Sugiyama S, Sato K, Katayose M, Suzuki H. The proper use of antibiotics for hospitalized children with respiratory syncytial virus infection. J Jpn Pediatr Soc, 110 : 762 766, 2006.

43. Matsumoto A, Takeyama A, Hashimoto K, Ito M, Katayose M, Kato K, Kawasaki Y, Hosoya M. Non-antibiotic treatment for pediatric outpatients with common cold inhibits the emergence of drug resistant pneumococci. Fukushima Medical Journal, 56 : 28-37, 2010.

44. Matsumoto A, Takeyama A, Hashimoto K, Ito M, Katayose M, Kato K, Kawasaki Y, Hosoya M. The trend of drug-resistant Streptococcus pneumoniae from nasopharynx of children. J Infect Chemother, 16 : 255-259, 2010.

45. Matsumoto A, Kawasaki Y, Hashimoto K, Katayose M, Kato K, Suzuki H, Hosoya M. The trend of drug-resistant Haemophilus influenzae from nasopharynx of children. Kansenshogaku Zasshi, 84 : 171-175, 2010.

46. Kosowska K, Jacobs MR, Bajaksouzian S, Koeth L, Appelbaum PC. Alterations of penicillin-binding proteins 1A, 2X, and 2B in Streptococcus pneumoniae isolates for which amoxicillin MICs are higher than penicillin MICs. Antimicrob. Agents Chemother, 48 : 4020-4022, 2004.

47. Cafini F, del Campo R, Alou L, Sevillano D, Morosini MI, Baquero F, Prieto J. Alterations of the penicillin-binding proteins and murM alleles of clinical Streptococcus pneumoniae isolates with high-level resistance to amoxicillin in Spain. J Antimicrob Chemother, 57 : 224-229, 2006.

48. Du Plessis M, Bingen E, Keith, KP. Analysis of penicillin-binding protein genes of clinical isolates of Streptococcus pneumoniae with reduced susceptibility to amoxicillin. Antimicrob Agents Chemother, 46 : 2349-2357, 2002.

49. Baquero F, Baquero-Antigao G, Cantón R, GarciaRey C. Antibiotic consumption and resistance selection in Streptococcus pneumoniae. J Antimicrob Chemother, 50 : 27-37, 2002.

50. Bagshaw SM, Kellner JD. Beliefs and behaviours of parents regarding antibiotic use by children. Can J Infect Dis, 12 : 93-97, 2001.

51. Palmer DA, Bauchner H. Parents' and physicians' views on antibiotics. Pediatrics, 99 : e6-11, 1997.

52. Mangione-Smith R, Elliott MN, Stivers T, McDonald LL, Heritage J. Ruling out the need for antibiotics : are we sending the right message ?. Arch Pediatr Adolesc Med, 160 : 945-952, 2006.

53. Stivers T, Mangione-Smith R, Marc N, Elliott MN, McDonald L, Heritage J. Why do physicians think parents expect antibiotics? What parents report vs what physicians believe. J Fam Pract, 52 : 140148, 2003.

54. Moro ML, Marchi M, Gagliotti C, DiMario S, Resi D, the "Progetto Bambini a Antibiotici [ProBA].". Why do paediatricians prescribe antibiotics? Results of an Italian regional project. BMC Pediatrics, 9 : 69, 2009.

55. Huang SS, Rifas-Shiman SL, Kleinman K, Kotch J, Schiff N, Stille CJ, Steingard R, Finkelstein JA. Parental knowledge about antibiotic use : results of a cluster-randomized, multicommunity inter- 
vention. Pediatrics, 119: 698-706, 2007.

56. Mangione-Smith R, Elliott MN, Stivers T, McDonald L, Heritage J, McGlynn EA. Racial/ ethnic variation in parent expectations for antibiotics: implications for public health campaigns. Pediatrics, 113 : e385-e394, 2004.

57. Hamm RM, Hicks RJ, Bemben DA. Antibiotics and respiratory infections : are patients more satisfied when expectations are met?. J Fam Pract, 43 : 56-62, 1996.

58. Marchetti F, Ronfani L, Nibali SC, Tamburlini G. Delayed prescription may reduce the use of antibiotics for acute otitis media. Arch Pediatr Adolesc Med, 159 : 679-684, 2005.

59. McCormick DP, Chonmaitree T, Pittman C, Saeed K, Friedman N, Tatsuo Uchida T, Baldwin CD. Nonsevere acute otitis media : A clinical trial comparing outcomes of watchful waiting versus immediate antibiotic treatment. Pediatrics, $115: 1455-$ 1465, 2005.

60. Spiro DM, Tay KY, Arnold DH, Dziura JD, Baker MD, Shapiro ED. Wait-and-see prescription for the treatment of acute otitis media : a randomized controlled trial. JAMA, 296 : 1235-1241, 2006.

61. Coco A, Vernacchio L, Horst M, Anderson A. Management of acute otitis media after publication of the 2004 AAP and AAFP clinical practice guideline. Pediatrics, 125 : 214-220, 2010.

62. Meropol SB, Glick HA, Asch DA. Age inconsistency in the American Academy of Pediatrics guidelines for acute otitis media. Pediatrics, 121 : 657668, 2008.

63. Hotomi M, Yamanaka N, Samukawa T, Suzumoto M, Sakai A, Shimada J, Ikeda Y, Faden H. Treatment and outcome of severe and non-severe acute otitis media. Eur J Pediatr, 164 : 3-8, 2005.

64. WHO. Global Programme for Vaccines and Immunizations (GPV). The WHO position paper on Haemophilus influenzae type b conjugate vaccines. Wkly Epidemiol Rec, 73 : 64-68, 1998.

65. WHO. Introduction of Haemophilus influenzae type b vaccine into immunization programmes : Department of Vaccines and Biologicals. WHO, 2000.

66. Peltola H, Salo E, Saxén H. Incidence of Haemophilus influenzae type $\mathrm{b}$ meningitis during 18 years of vaccine use : observational study using routine hospital data. BMJ, 330 : 18-19, 2005.

67. Shao PL, Chie WC, Wang CY, Yang CY, Lu CY, Chang LY, Huang LM, Lee CY. Epidemiology of Haemophilus influenzae type b meningitis in Taiwan, 1997 and 2000. J Microbiol Immunol Infect, 37 : 163-168, 2004.

68. de Andrade ALSS, de Andrade JG, MartelliCM, e Silva SA, de Oliveira RM, Costa MSN, Laval BC, Ribeiro LHV, Di Fabio JL. Effectiveness of Haemophilus influenzae b conjugate vaccine on childhood pneumonia: a case-control study in Brazil. Int J Epidemiol, 33 : 173-181, 2004.

69. Campos J, Hernando M, Román F, Pérez-Vázquez M, Aracil B, Oteo J, Lázaro E, de Abajo F. Group of invasive Haemophilus infections of the autonomous community of Madrid, Spain. Analysis of invasive Haemophilus influenzae infections after extensive vaccination against $H$. influenzae type b. J Clin Microbiol, 42: 524-529, 2004.

70. Cowgill KD, Moses Ndiritu M, Nyiro J, Slack MPE, Chiphatsi S, Ismail A, Kamau T, Mwangi I, English M, Newton CRJC, Feikin DR, Scott JAG. Effectiveness of Haemophilus influenzae type b conjugate vaccine introduction into routine childhood immunization in Kenya. JAMA, 296 : 671-678, 2006.

71. Adegbola RA, Secka O, Lahai G, Lloyd-Evans N, Njie A, Usen S, Oluwalana C, Obaro A, Weber M, Corrah T, Mulholland K, McAdam K, Greenwood B, Milligan BPJM. Elimination of Haemophilus influenzae type b (Hib) disease from the Gambia after the introduction of routine immunisation with a Hib conjugate vaccine: a prospective study. Lancet, 366 : 144-150, 2005.

72. Meissner HC, Pickering LK. Control of disease attributable to Haemophilus influenzae type b and the national immunization program. Pediatrics, 110 : 820-823, 2002.

73. WHO. Pneumococcal conjugate vaccine for childhood immunization WHO position paper. Wkly Epidemiol Rec, 82 : 93-104, 2007.

74. CDC. Pneumonia hospitalizations among young children before and after introduction of pneumococcal conjugate vaccine-United States, 19972006. MMWR, 58 : 1-4, 2009.

75. Hsu HE, Shutt KA, Moore MR, Beall BW, Bennett NM, Craig AS, Farley MM, Jorgensen JH, Lexau CA, Petit S, Reingold A, Chaffner W, Thomas A, Whitney CG, Harrison LH. Effect of pneumococcal conjugate vaccine on pneumococcal meningitis. N Engl J Med, 360 : 244-256, 2009.

76. Tsigrelis C, Tleyjeh IM, Lahr BD, Nyre LM, Virk A, Baddour LM. Decreases in case-fatality and mortality rates for invasive pneumococcal disease in Olmsted County, Minnesota, during 19952007 : A population-based study. Clin Infect Dis, 47 : 1367-1371, 2008.

77. Katsarolis I, Poulakou G, Analitis A, Matthaiopoulou I, Roilides E, Antachopoulos C, Kafetzis DA, Daikos GL, Vorou R, Koubaniou C, Pneumatikos I, Samonis G, Syriopoulou V, Giamarellou H, Kanellakopoulou K. Risk factors for nasopharyngeal carriage of drug-resistant Streptococcus pneumoniae : data from a nation-wide surveillance study in Greece. BMC Infect Dis, 9 : 120, 2009.

78. Hammitt LL, Bruden DL, Butler JC, Baggett HC, Hurlburt DA, Reasonover A, Hennessy TW. 
Indirect effect of conjugate vaccine on adult carriage of Streptococcus pneumoniae : an explanation of trends in invasive pneumococcal disease. J Infect Dis, 193 : 1487-1494, 2006.

79. Millar EV, Watt JP, Bronsdon MA, Dallas J, Reid R, Santosham M, O'Brien KL. Indirect effect of 7-valent pneumococcal conjugate vaccine on pneumococcal colonization among unvaccinated household members. Clin Infect Dis, 47 : 989-996, 2008.

80. O'Brien KL, Millar EV, Zell ER, Bronsdon M, Weatherholtz R, Reid R, Becenti J, Kvamme S, Whitney CG, Santosham M. Effect of pneumococcal conjugate vaccine on nasopharyngeal colonization among immunized and unimmunized children in a community-randomized trial. J Infect Dis, 196 : 1211-1220, 2007.

81. Dagan R. Impact of pneumococcal conjugate vaccine on infections caused by antibiotic-resistant Streptococcus pneumoniae. Clin Microbiol Infect, 3 : 16-20, 2009.

82. Kyaw MH, Lynfield R, Schaffner W, Creig AS, Hadler J, Reingold A, Thomas AR, Harrison LH, Bennett N, Farley MM, Facklam RR, Jorgensen JH, Besser J, Zell E, Schuchat A, Whitney CG. Effect of introduction of the pneumococcal conjugate vaccine on drug-resistant Streptococcus pneumoniae. N Eng J Med, 354 : 1455-1463, 2006.

83. Frazão N, Brito-Avô A, Simas C, Saldanha J, Mato R, Nunes A, Sousa NG, Carrico JA, Almeida JS, Santos-Sanches L, de Lencastre H. Effect of the seven-valent conjugate pneumococcal vaccine on carriage and drug resistance of Streptococcus pneumoniae in healthy children attending day-care centers in Lisbon. Pediatr Infect Dis J, 24 : 243-252, 2005.

84. Shin S, Shin YJ, Ki M. Cost-benefit analysis of Haemophilus influenzae type b immunization in Korea. J Korean Med Sci, 23 : 176-184, 2008.

85. Broughton EI. Economic evaluation of Haemophilus influenzae type B vaccination in Indonesia : a cost-effectiveness analysis. J Public Health, 29 : 441-448, 2007.

86. Vespa G, Constenla DO, Pepe C, Safadi MA, Berezin E, Moraes JC, de Campos CAH, Araujo DV, Andrade ALSS. Estimating the cost-effectiveness of pneumococcal conjugate vaccination in Brazil. Rev Panam Salud Publica, 26 : 518-528, 2009.

87. Sohn HS, Suh DC, Jang E, Kwon JW. Economic evaluation of childhood 7-valent pneumococcal conjugate vaccination in Korea. J Manag Care Pharm, 16 : 32-45, 2010.

88. Kamiya K, Miyazaki C, Nakano T, Sasaki M. Analysis of the disease burden caused by Hib meningitis and cost-effectiveness analysis of Hib vaccines. J JPN Pediatr Soc, 110 : 1214-1221, 2006.

89. Chiappini E, Galli L, Bonsignori F, Venturini E, Principi N, de Martino M. Self-reported pediatricians' management of the well-appearing young child with fever without a source : first survey in an European country in the anti-pneumococcal vaccine era. BMC Public Health, 9 : 300, 2009.

90. Finkelstein JA, Huang SS, Kleinman K, RifasShiman SL, Stille CJ, Daniel J, Schiff N, Steingard R, Soumerai SB, Ross-Degnan D, Goldmann D, Platt R. Impact of a 16 -community trial to promote judicious antibiotic use in Massachusetts. Pediatrics, 121 : e15-23, 2008.

91. Huang SS, Rifas-Shiman SL, Kleinman K, Kotch J, Schiff N, Stille CJ, Steingard R, Finkelstein JA. Parental knowledge about antibiotic use : results of a cluster-randomized, multicommunity intervention. Pediatrics, 119: 698-706, 2007.

92. Trepka MJ, Belongia EA, Chyou PH, Davis JP, Schwartz B. The effect of a community intervention trial on parental knowledge and awareness of antibiotic resistance and appropriate antibiotic use in children. Pediatrics, 107 : e6, 2007.

93. Belongia EA, Sullivan BJ, Chyou PH, Madagame E, Reed KD, Schwartz B. A community intervention trial to promote judicious antibiotic use and reduce penicillin-resistant Streptococcus pneumoniae carriage in children. Pediatrics, 108 : 575583, 2001.

94. Perz JF, Craig AS, Coffey CS, Jorgensen DM, Mitchel E, Hall S, Schaffner W, Griffin MR. Changes in antibiotic prescribing for children after a community-wide campaign. JAMA, 19: 31033109, 2002.

95. Arnold SR, Straus SE. Interventions to improve antibiotic prescribing practices in ambulatory care. Cochrane Database Syst Rev, 19 : CD003539, 2005.

96. Wheeler JG, Fair M, Simpson PM, Rowlands LA, Aitken ME, Jacobs RF. Impact of a waiting room videotape message on parent attitudes toward pediatric antibiotic use. Pediatrics, 108: 591596, 2001. 